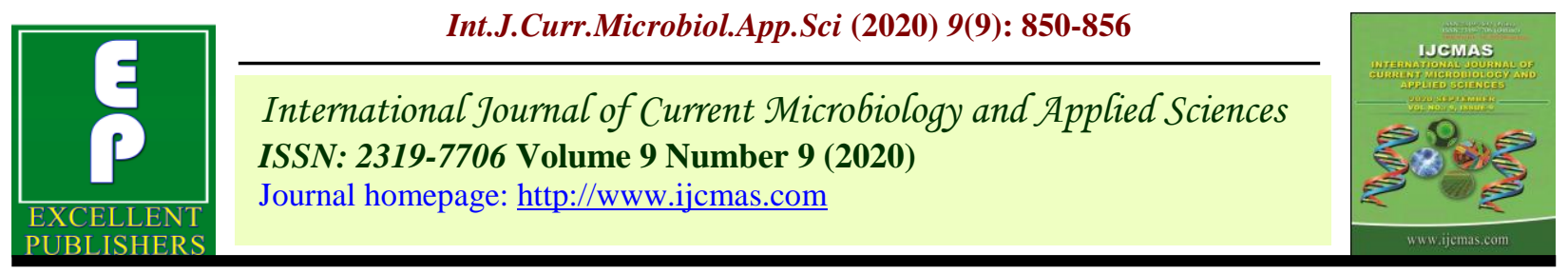

Original Research Article

https://doi.org/10.20546/ijcmas.2020.909.107

\title{
Management of Menstrual Waste among Rural Families
}

\author{
V. Kavitha Kiran and K. Yashoda* \\ All India Coordinated Research Project on Home Science, Human Development Component, \\ PGRC, PJTSAU, Rajendranagar, Hyderabad-30, Telangana, India \\ *Corresponding author
}

\section{A B S T R A C T}

\section{Keywords}

Menstrual waste,

Personal and

Environmental

Hygiene,

Reproductive tract infections, Sanitary, Incinerators, Rural families

\section{Article Info}

Accepted:

10 August 2020

Available Online:

10 September 2020

\begin{abstract}
The study was planned to assess the Management of Menstrual Waste among Rural Families. Girls and women have very less or no knowledge about reproductive tract infections caused due to ignorance of personal hygiene and menstruation time. In rural areas, women do not have access to sanitary products or they know very little about the types and method of using them or are unable to afford such products due to high cost. So women mostly rely on reusable cloth pads which they wash and use again. Adolescent girls mostly used the sanitary pads. Exploratory study was conducted with focused group discussions and self-reported questionnaire to assess the menstrual waste management among rural women. The study was carried out in Rural Telangana area. Major findings of the study were $56 \%$ of rural women dispose their napkins in the garbage, $16 \%$ of the women mentioned that they bury them, and $17 \%$ women burn the soiled napkins. After Installation of Incinerators in the Village 62\% using incinerators for proper disposal of napkins. These incinerators are a sigh of relief for the school going girls and working women. It helped in decreasing absenteeism of adolescent girls during menstrual period and also improved the Personal and Environmental Hygiene. The study findings suggest that there is a need to educate and create awareness about the environmental pollution and health hazards associated with them.
\end{abstract}

\section{Introduction}

Menstruation wastes are the wastes that are generated by a female in her reproductive years. These wastes are produced during menstruation commonly known as menses, periods, or monthly bleeding cycle. The menstrual cycle has three phases, that is, follicular phase (proliferative), ovulation phase, and luteal phase (secretory). Menstruation is regulated by hormones; in this process, endometrium, lining of uterus, gradually thickens and sheds of and causes bleeding that normally last for 3-5 days and occasionally up to 7 days. Menstruation sheds two-thirds of the endometrial lining. In addition to blood, menstrual fluid contains mucus and vaginal secretions. The menstrual flow varies from female to female and may be more or less at the beginning of menses or may change throughout the cycle. The colour of the menstrual fluid varies between red, bright red, and dark brown to black. Menstrual fluid may or may not have 
unpleasant odour especially when it comes in contact with air.

Sanitary waste disposal has become an increasing problem in India as the plastic used in disposable sanitary napkins are not biodegradable and lead to health and environmental hazards. The impact is more pronounced because of the unorganized ways of municipal solid waste management and poor community collection, disposal and transportation networks in the cities and villages.

Further, one major issue of sanitary waste has always been their categorization, i.e., whether it is biomedical or plastic waste. Soiled napkins, diapers, condoms, tampons and blood-soaked cotton, which are household waste according to the Solid Waste Management (SWM) Rules, 2016, are being disposed after segregation into biodegradable and non-biodegradable components.

However, the Biomedical Waste Management Rules, 2016 indicate that items contaminated with blood and body fluids, including cotton, dressings, soiled plaster casts, lines and bedding, are bio-medical waste and should be incinerated, autoclaved or microwaved to destroy pathogens. The lack of concern for sanitary waste management in our country is reflected in the fact that there is no reliable statistics on the subject. Due to the lack of segregation of waste, there is hardly any documentation in this area, so through instructions for handling and management of sanitary waste are essential. As per the study conducted in 2011, titled 'Sanitary Protection: Every woman's health right' estimated that only $12 \%$ of the 335 million menstruating women have access to disposable sanitary napkins. Environment portal Down to Earth estimated that 432 million pads are disposed every month.

\section{Rationale}

As per MHM guidelines, 'Safe disposal' means ensuring that the process of destruction of used and soiled materials is done without human contact and with minimal environmental pollution and 'Unsafe disposal' means throwing used cloth into ponds, rivers, or in the fields exposes others in the area to decaying material and should be avoided. Offsite disposal can be organized with the communal or town solid waste collection and management system. If a hospital with a safe and treatment unit for hazardous waste is nearby, this might be a best solution to explore. However, this is unfortunately not a viable option for many rural schools, and transport will be a logistical and financial challenge. Options for on-site disposal include disposal deep burial, composting, pit burning and incineration. The right option depends on key factors such as amount and type of materials, the available budget (investment and O\&M costs) and environmental considerations. Burning in open heap should be totally avoided. If burning is the only option, a deep pit should be used.

\section{Materials and Methods}

Sample was identified from the adopted villages namely Pendyala, Kalvakol, Subhanpura, Kollapadkal and Rama chandraguda (5) of Maheshwarammandal, RR District, Hyderabad.

Research design: Exploratory study was carried out infield practice area of the MaheswaramMandal, Ranga Reddy District.

Sample: The study was undertaken among the 120 adolescent's girls and women in the Agrarian families. This study was carried out in a period of 6 months 
Tools: Management of Menstrual waste checklist was developed by AICRP-CD, Hyderabad Unit (2019) to find out the practices of adolescent girls with regard to menstrual waste.

\section{Types of Absorbents Used during Menstruation}

\begin{tabular}{|l|l|l|}
\hline $\begin{array}{l}\text { Type of Material } \\
\text { used }\end{array}$ & $\begin{array}{l}\text { Sanitary } \\
\text { Napkin }\end{array}$ & Cloth \\
\cline { 3 - 4 } & $96(80 \%)$ & $24(20 \%)$ \\
\hline
\end{tabular}

With regard to type of material used, it was fund that $80 \%$ of adolescent girls used sanitary napkins, while $20 \%$ used cloth. In all government high schools sanitary napkins are provided to adolescent girls, so majority of them use sanitary napkins.

\section{Menstrual Waste Disposal Techniques}

Disposing in the open: The disposal of sanitary napkins depends on the location where women are disposing soiled napkins. Often their behaviour differs when they are not at home; $34 \%$ of the women tend to leave the soiled napkins unwrapped in the corners or they throw the used pad in dustbins without wrapping them.

Disposing in the dustbin/garbage: When at home $56 \%$ of Rural women dispose their napkins in the garbage; most of the times they wrap it and throw it but when not at home there is a tendency of throwing the pad without wrapping it, in the dustbin.

Burying the menstrual waste in a pit: Some rural women bury the menstrual waste in a pit; many would wash the used napkins and then bury the same in a pit. it was discovered that girls using napkins in school carry the used one's home and around 16\% of the women interviewed would bury them or dispose them alongside ponds.
Burning the menstrual waste: in the above mentioned study $17 \%$ women burn the soiled napkins. The burning of used pads is prevalent in rural areas than in urban areas as women have to take care of the final disposal of pads there; whereas in urban areas women forget about the consequences of disposal after they have thrown it in the dustbin.

\section{Using incinerators or special disposal dustbins}

In Villages DWACRA buildings and schools have started $62 \%$ using incinerators for proper disposal of napkins. These incinerators are a sigh of relief for the school going girls and working women.

Flushing the soiled napkins: as mentioned before the disposal habit changes according to the place; in public places, depending on the toilet type; for example when women are using flush toilets they try to flush the soiled napkins and if it doesn't get flushed they may wrap it and throw it in the dustbins. Things in this context might be changing now but because of lack of information on disposal facilities only $3 \%$ women even today flush used napkins in the toilet.

It was interesting to note from the study that $48 \%$ of the girls miss school for 1-2 days during their menstruation every month while $52 \%$ were absent for 3-5days from school because of the menstrual period. The reason for this is lack of proper safe disposal facilities and common health issues.

As part of the project Incinerators were installed in the adopted villages and awareness programmes were conducted on Menstrual Hygiene Practices. In addition capacity building programmes related to nutrition, proper diet and meditation were conducted to address the health issues of adolescent girls during the menstrual period. 
After Installation of the Incinerators in the Schools and capacity building programs, it was found that absenteeism of adolescent girls decreased, as they have safe Through Installation of the Incinerators Increasing the Attendance percentage of the adolescent Girls and improved their Personal and Environmental Hygiene.

Women have to compromise with their menstrual needs and personal hygiene. Decisions related to constructing toilets in houses are also taken by male members. So it is a big barrier in menstrual hygiene as women find it difficult in cleaning and changing menstrual materials in privacy. Women and girls who have toilets at home feel shy and embarrassed as the drain that leads out is not covered and there is a chance of seeing blood flowing in drain by others. In some reports, it was found that parents did not allow boys to discuss such topic as they were not important for their future, so the boys received information about menstruation from friends and Internet which is inaccurate and incomplete.

Most men do not know about the menstruation and physiological changes in women during menstruation and menstrual cycle, so it is difficult to change their perception regarding menstruation and menstrual hygiene. Due to unwillingness, myths, prejudices, and misconceptions, it is difficult to talk about menstruation with men and boys. But by engaging them into group discussions and regular community meetings, their perception can be changed and make them aware about their role regarding menstrual hygiene management (Fig. 1 and 2).

Fig.1 Capacity building programmes on menstrual waste management
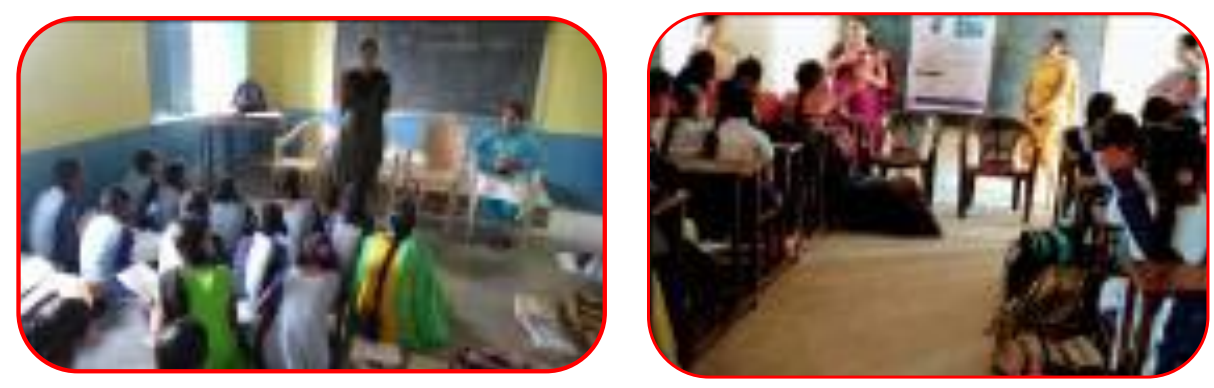

Fig.2 Incinerator installed in the toilet for easy sanitary products disposal

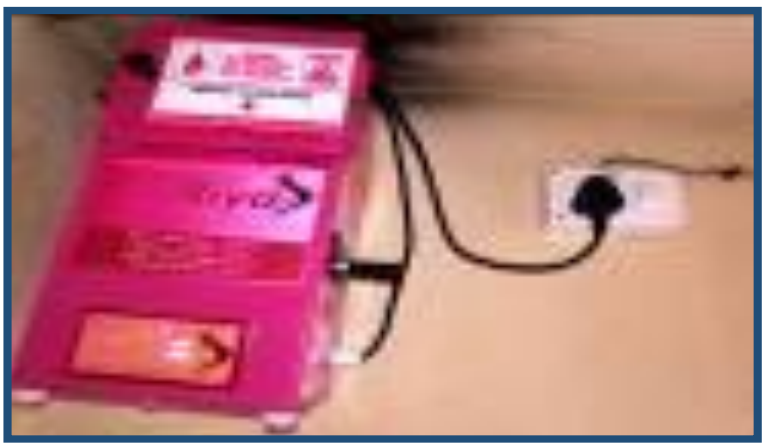


Role of teachers in creating awareness regarding menstruation and menstrual waste management

In schools, teachers can make the school environment girl/women friendly to manage menstruation with dignity. Sex education in schools helps adolescents to discover their sexual identity, to protect themselves from sexual abuse, unwanted pregnancies, and sexually transmitted diseases, and to know physiological changes occurring in the body and how to take care of personal hygiene. Different views of parents, teachers, and society affect sex education being taught in schools and colleges. Cultural, religious, and social barriers also create hindrance in the path of sex education.

Our education sector plays an important role in child's growth and development by allowing them to respond to changes and challenges they are facing in day-to-day life. But many times it avoids issues related to the menstruation and menstrual hygiene management by considering it one's personal matter and should be discussed within the house. Menstruation is a silent issue in girl's life which is further affected by teacher's attitude, school environment, and infrastructure. Because of this, many girls remain absent from schools during this time. Sex education is often neglected from the school curriculum which negatively impacts the student's life.

They get information about puberty, sexual intercourse, menstruation, and other physiological changes in one's body from books, friends, and Internet which may be incomplete or inaccurate. Due to lack of knowledge and social interaction, teasing and taunting are common in schools. This makes it difficult for a girl student to survive in this environment, so they choose to be absent from school.
Strategies for the management of menstrual waste

Disposal of menstrual waste is of major concern as it affects health and environment. There is a need for effective menstrual materials which needs less and cost-effective management.

Companies dealing with manufacturing of sanitary pads or other articles should disclose the information on the pads regarding the chemical composition of the pads so that appropriate technologies could be used for their disposal and treatment.

Environment-friendly chemicals should be used by manufacturers of sanitary products to stop soil, water pollution and to fasten the decomposition process.

Guidance regarding menstrual management to adolescent girls and women is a much needed step. Menstrual hygiene management should be an integral part of education curriculum.

There should be a separate collection system for the menstrual wastes without affecting the privacy and dignity of women. Specific sanitary dispensers to collect menstrual waste should be installed.

Incinerators are a better option for disposal but should be operated in a controlled environment so that harmful gasses emitted will not harm larger area content. So they are easily decomposable as compared to other commercial products.

The Incinerator burns the sanitary napkins and reduces them into micro ash, which is collected in the inbuilt ash-tray. There is also a 2-inch emission outlet at the top of the incinerator for pushing out the fumes developed during the incineration. 
In conclusion the menstrual hygiene should be promoted by implementing a course on menstruation and menstrual hygiene management. Teachers should be educated and trained to impart knowledge about menstruation and menstrual hygiene management among students. Social and electronic media also play an important role to make the girls and women aware about the latest menstrual products, different manufacturers, government policies, and so forth. Subsidies should be given on menstrual products so that every girl/women can afford them easily. Some organizations should come forward to educate rural people about menstruation, menstrual hygiene management, importance of toilets at homes, hand washing, diseases related to reproductive tract due to poor hygiene, and so forth. Emphases should be given on the use of reusable sanitary or cloth pads to overcome the problem of disposal. Girls and women should be aware of the consequences of disposing used menstrual products in open or flushing them in toilets. Dustbins with proper lids should be placed in the toilets. If possible, incinerators should be installed at homes, schools, and community levels. This study reveals that lack of privacy is a major concern both in household and in schools. Also, ignorance, misconceptions, unsafe practices, and illiteracy of the mother and child regarding menstruation are the root causes of many problems. So, there is a big need to encourage adolescents at school levels to practice safe and hygienic behaviours. Mainly through Installation of Incinerators in Schools increased the School attendance percentage of the adolescent girls and also improved their Personal and Environmental hygiene.

\section{References}

Jasper, C., T.-T. Le, and J. Bartram, "Water and sanitation in schools: a systematic review of the health and educational outcomes," International Journal of Environmental Research and Public Health, vol. 9, no. 8, pp. 2772-2787, 2012.

Shoemaker, D. 2008. Proper procedure for sanitary napkin disposal," Cleaning and Maintenance Management, vol. 45, no. 4, pp. 33-37.

Goldman, J. D. G., 2008. Responding to parental objections to school sexuality education: A selection of 12 objections," Sex Education: Sexuality, Society and Learning, vol. 8, no. 4, pp. 415-438.

Narayan, K. A., D. K Srinivastava, P. J. Pelto, and S. Veerapmmal, "Puberty Rituals, Reproductive Knowledge and Health of Adolescent Schoolgirls in South India," Asia-Pacific Population Journal, vol. 16, pp. 225-238, 2001.

Jogdand, K. and P. A. Yerpude, "Community based study on menstrual hygiene among adolescent girls," Indian Journal of Maternal and Child Health, vol. 13, no. 3, pp. 1-6, 2011.

Sommer M., M. Kjellen, and C. Pensulo, 'Girls' and women's ' unmet needs for menstrual hygiene management (MHM): Te interactions between MHM and sanitation systems in low income countries," Journal of Water Sanitation and Hygiene for Development, vol. 3, no. 3, pp. 283-297, 2013

Garg R., S. Goyal, and S. Gupta, "India moves towards menstrual hygiene: Subsidized sanitary napkins for rural adolescent girls - Issues and challenges," Maternal and Child Health Journal, vol. 16, no. 4, pp. 767-774, 2012

Nagar, S. and K. R. Aimol, "Knowledge of Adolescent Girls Regarding Menstruation in Tribal Areas of Meghalaya," Studies of Tribes and Tribals, vol. 8, no. 1, pp. 27-30, 2017.

Pokharel, S., A. Kulczycki, and S. Shakya, 
"School-Based Sex Education in Western Nepal: Uncomfortable for Both Teachers and Students," Reproductive Health Matters, vol. 14, no. 28, pp. 156161, 2006

Aniebue. U., P. Aniebue, and T. Nwankwo.
2010. Te impact of premenarcheal training on menstrual practices and hygiene of Nigerian school girls," Pan African Medical Journal, vol. 2, no. 9.

\section{How to cite this article:}

Kavitha Kiran, V. and Yashoda, K. 2020. Management of Menstrual Waste among Rural Families. Int.J.Curr.Microbiol.App.Sci. 9(09): 850-856.

doi: https://doi.org/10.20546/ijcmas.2020.909.107 